\title{
The impact of temperature-humidity index on blood morphology and $\beta$-hydroxybutyrate in different sheep breeds
}

\author{
Jurgita Autukaité ${ }^{1}$, Indrè Poškiené ${ }^{1}$, Vida Juozaitienè ${ }^{2}$, Ramūnas Antanaitis ${ }^{1}$, \\ Henrikas Žilinskas ${ }^{1}$
} Lithuanian University of Health Sciences, ${ }^{1}$ Veterinary Academy, ${ }^{2}$ Department of Animal Breeding,
Veterinary Academy, Kaunas, Lithuania

Received November 18, 2019

Accepted September 14, 2020

\begin{abstract}
Climatic variations directly affect the animals, changing their physiology. Several factors such as species, breed, sex, age, nutrition, diseases, physiological stage, and seasonal variations can affect the pattern of haematological values. Quantitative and morphological changes in blood cells are associated with higher temperatures and humidity. Sixty-seven sheep (3 years old, not pregnant, clinically healthy) were used in the study to determine the effect of the temperaturehumidity index (THI) and breed on morphological blood indices and $\beta$-hydroxybutyrate (BHB). The sheep were divided into groups by the breed ( 4 breeds) and the THI ( 2 classes). The blood samples from each animal were collected monthly. Significant differences between the values of leukocytes (WBC), neutrophils (NEU), erythrocytes (RBC), haemoglobin (HGB), haematocrit (HCT), mean corpuscular volume (MCV), mean corpuscular haemoglobin (MCH), mean corpuscular haemoglobin concentration (MCHC), lymphocytes (LYM), monocytes (MON) and platelet count (PLT) in THI groups were observed. In THI 1 , the mean values of MCHC $(5.68 \%$, $P<0.05)$, MCH $(0.52 \%)$, and HCT $(4.90 \%, P<0.05)$ were higher compared to those in THI 2. Multivariate test showed a significant effect of breed on NEU $(P<0.05)$, RBC $(P<0.05)$, HGB $(P<0.05)$ and MCHC $(P<0.05)$. The concentration of BHB in group THI 2 was by $12.9 \%$ higher $(P<0.05)$, compared to group THI 1. A significant effect of the breed $(P<0.05)$ and THI class $(P<0.05)$ on BHB was determined, whereas the impact of breed interaction with the THI was found to be non-significant. The observations reported in this study suggest that the response to temperature is dependent on animal breed. It was found that both morphological blood indices and $\mathrm{BHB}$ were affected by the temperature-humidity index.
\end{abstract}

Ovine, heat stress, climate change

Climatic variations directly affect the animals, changing their physiology (Ribeiro et al. 2018). The impact of climatic changes has caused much loss in livestock production (Salama et al. 2014) - a fact that generates the need for detailed studies to better understand the mechanisms of animal adaptation to a changing climate.

The severity of thermal stressor should not be determined only by the temperature factor. It is important to include also the humidity level as it has a significant impact on perceptible temperature (Correa et al. 2012). The most common empirical model is the temperature-humidity index (THI), which is a combination of effects of temperature and humidity (Gaughan et al. 2011). The THI integrates temperature and humidity into one value, which allows an objective comparison of environmental conditions. Currently, the index is broadly used, allowing investigators to better understand the effects of climatic conditions. However, the index should not be treated as an absolute value to determine the thermal nuisance. It is important to be aware of the effect of factors such as air movement or sun radiation on the physiological status of animals (Marai et al. 2007)

Changes of environmental temperature and humidity have a significant impact on physiological processes. The phenomenon of mammalian sensitivity to thermal stress, especially in small ruminants, is widely reported in the literature (Caroprese 2008). The

Address for correspondence:

Jurgita Autukaitè

Laimos St. 9-34, Kaunas, Lithuania
Phone: +37067802711

E-mail: jurgita.autukaite@1smuni.lt

http://actavet.vfu.cz/ 
extent of this tolerance largely depends on various factors, mainly on the physiological state of the organism, breed and anionic-cationic compounds in the blood (Srikandakumar et al. 2003). Marai and Haeeb (2010) defined thermal stress as a state in which the physiological mechanisms of animal body activate to maintain the thermal balance of the body when exposed to elevated temperature. The experiments conducted on Omani and Australian Merino sheep confirmed a correlation between the environmental temperature and humidity and blood indices (Srikandakumar et al. 2003). The blood system is sensitive to temperature changes and is an important indicator of physiological responses to stressors (Bezerra et al. 2008; Al-Eissa et al. 2012). The results show the variations in haematocrit values, mean erythrocyte count and haemoglobin (Ribeiro et al. 2018). Erythrocytes vary in diameter and thickness depending on the breed and nutritional status of the animal. However, they are capable of changing form as they pass through capillaries (McManus et al. 2011). $\beta$-hydroxybutyrate (BHB) is an important metabolic regulator in plasma and serum during climatic changes (Aleena et al. 2016). Ketone bodies come from volatile fatty acids (mainly butyrate, which is converted to BHB across the rumen epithelium) and fat mobilization (Salama et al. 2014). Neither weekly nor mean total concentrations of BHB were affected by the THI, indicating no mobilization of body fat (Al-Dawood 2017). It might be considered as a metabolic adaptive response during thermal stress, although some contradictory findings were observed in heat-stressed dairy goats (Salama et al. 2014). When lacking thermal comfort, an animal seeks ways to lose heat. This involves a series of adaptations of the respiratory, circulatory, excretory, endocrine, and nervous systems of animals reared in warm regions (McManus et al. 2009). The coordination of all of these systems to maintain the productive potential varies between species, breeds, and individuals within the same breed (Marai and Haeeb 2010). It is important to note that while research on the temperature-humidity effect in sheep was discontinued, sheep have been genetically altered by the selection practices since the 1960s (Beatty et al. 2008).

In the present study, the hypothesis of the possible impact of the temperature and humidity on blood morphological indices and $\beta$-hydroxybutyrate (BHB) and the difference in blood morphology between four different sheep breeds was raised. Accordingly, the objective of the present study was to determine the impact of the THI on blood morphological indices and $\mathrm{BHB}$ as well as the difference in blood morphology between four different breeds.

\section{Location, animals and experimental design}

The experiment was conducted on four (A, B, C, D) sheep farms in Eastern Europe. Farm coordinates of the location: A - 54.776651, 24.820980 (Suffolk breed), farm B - 54.723938, 24.781913 (Merino breed), farm C - 55.067735, 22.373470 (Lithuanian Blackheaded breed), farm D - 55.762014, 23.746363 (Charolaise breed). The climate of the country is transitional between the maritime type of Western Europe and the continental type present farther east, characterized by warm, dry summers and fairly severe winters. The annual average temperature is $10.5 \pm 1.0^{\circ} \mathrm{C}$ and the mean annual air humidity is $77.6 \pm 2.0 \%$. The experimental period lasted from September 2018 to April 2019 and comprised three climatic seasons: autumn (September to November), winter (December to February) and spring (March to April). Sixty-seven sheep (on average $3.0 \pm 0.5$ years old) were selected based on the following criteria: not pregnant during the entire investigation period, clinically healthy and without any signs of disease after a precise clinical examination (an average rectal temperature of $38.5^{\circ} \mathrm{C}$, rumen motility $3-4 \times$ per $2 \mathrm{~min}$ ). Farms carry out the monitoring of infectious diseases; routine deworming is done twice a year.

The animals were divided into four experimental groups: Suffolk $(\mathrm{n}=20)$, Merino $(\mathrm{n}=20)$, Lithuanian Blackheaded $(n=20)$, and Charolaise $(n=7)$. Body weights of animals in the groups were roughly equal (on average $35 \mathrm{~kg}$ ). The animals were kept in similar conditions in a stable and were fed at the same time throughout the year, with the rations nutritionally balanced according to their physiological needs. The sheep were fed grain oats at doses of $0.2 \mathrm{~kg}$ per head (100\% of intake), grass hay (Timothy grass, Red clover, White clover, alfalfa, rye grass, quack grass), and water was provided at libitum.

By the testing date, the sheep were divided into groups by the breed ( 4 breeds) and the temperature-humidity index (THI) (2 classes). The average daily values of humidity and air temperature in the farm zone were obtained 
from a nearby weather station ( $2 \mathrm{~km}$ away). Measurements were done every hour. The daily THI values were calculated using the following equation (a) by Marai et al. (2007):

$\mathrm{THI}=\mathrm{T}-(0.31-0.0031 \times \mathrm{RH}) \times(\mathrm{T}-14.4)(\mathrm{a})$,

where $\mathrm{T}$ is the dry-bulb temperature and $\mathrm{RH}$ is relative humidity. The average daily values of temperature and relative humidity were used to calculate the daily values of the THI that were analysed in this study. Based on the THI value (536 observations), two THI groups were created: Group THI 1) $20>$ THI > 10 (498 records, mean $\mathrm{THI}=11.08 \pm 0.58$, temperature $9.6 \pm 1.0^{\circ} \mathrm{C}$ and air humidity $\left.77.4 \pm 2.0 \%\right)$; Group THI 2$) \mathrm{THI} \geq 20$ (38 records, mean $\mathrm{THI}=22.25 \pm 0.90$, temperature $25.6 \pm 1.0^{\circ} \mathrm{C}$ and air humidity $80.21 \pm 3.40 \%$ ).

\section{Measurements}

The blood samples from each animal were collected monthly, from the jugular vein in a vacuum tube system containing 10\% EDTA (McManus et al. 2011). The total number of blood samples were 536 (Suffolk $\mathrm{n}=160$, Merino $\mathrm{n}=160$, Lithuanian Blackheaded $\mathrm{n}=160$, Charolaise $\mathrm{n}=56$ ). The samples were refrigerated at $8{ }^{\circ} \mathrm{C}$ and transported immediately to the laboratory for analysis. Values were determined for erythrocytes (RBC), haemoglobin (HGB), haematocrit (HCT), mean corpuscular volume (MCV), mean corpuscular haemoglobin $(\mathrm{MCH})$, mean corpuscular haemoglobin concentration (MCHC), leukocytes (WBC), neutrophils (NEU), lymphocytes (LYM), monocytes (MON), and the platelet count (PLT). The morphological indices were evaluated using the automatic analyzer MS4-5 VET (Melet Schloesing Laboratories, France 2012). For the BHB, blood samples were collected from the jugular vein in a vacuum tube system containing $10 \%$ EDTA. The identification of $\beta$-hydroxybutyrate (BHB) values was performed using the express diagnostic kit Free Style Optium Neo $\mathrm{H}$ (Abbott Diabetes Care Inc., United Kingdom 2013).

\section{Data analysis and statistics}

In the present study, the blood indices of the tested animals were analysed using the IBM SPSS Statistics (version 20.0, IBM, Munich, Germany) software. The descriptive statistics for blood indices was presented as mean \pm standard error $(M \pm S E)$. Normal distribution of data was assessed using Kolmogorov-Smirnov test. A two-factor multivariate ANOVA model was used to determine the influence of fixed factors - the breed and the THI, and the interaction between the breed and the THI in relation to blood indicators:

$$
\mathrm{y}_{\mathrm{ijk}}=\mu+\mathrm{B}_{\mathrm{i}}+\mathrm{T}_{\mathrm{j}}+\mathrm{BT}_{\mathrm{ij}}+\mathrm{e}_{\mathrm{k}}
$$

where $\mathrm{y}$ - blood indicator, $\mu$ - population mean, B - breed, T - the THI class, BT - the interaction between the breed and the THI class, e - a random error. The results were considered to be reliable at a $P$ level $<0.05$.

To test the hypothesis whether the blood indices and THI classes of the evaluated breeds were significantly different or similar, multivariate test with the Tukey procedure was used for subsequent analysis.

The research was performed according to the provisions of the Law No VIII-500 of the Republic of Lithuania of 6 November 1997 on the Care, Welfare and Use of Animals (Official Gazette No 108 of 28 November 1997), the Order No 4-361 of the State Veterinary Service of the Republic of Lithuania of 31 December 1998 on the Breeding, Care and Transportation of Laboratory Animals and the Order No 4-16 of the State Veterinary Service of the Republic of Lithuania of 18 January 1999 on the Use of Laboratory Animals for Scientific Tests. The study's approval number was PK014606.

\section{Results}

\section{The effect of the THI and breed on morfological blood indices}

In the present study, significant differences between the WBC, NEU, RBC, MCV, MCH, and PLT values in the THI groups (Table 1$)$ were estimated. In group THI $1, \mathrm{MCHC}(5.68 \%$, $P<0.05), \mathrm{MCH}(0.52 \%)$, and $\mathrm{HCT}(4.90 \%, P<0.05)$ were higher compared to group THI 2 . The mean values of other blood morphological indicators were higher in group THI 2 compared to group THI 1. The greatest differences were estimated for the mean values of NEU $-40.40 \%$ and PLT $-59.93 \%(P<0.05)$, the lowest for HGB and HCT $-1.60-1.88 \%$.

The analysis of blood indices by breed (Table 1$)$ showed a significantly higher $(23.17 \%)$ concentration of LYM in the Suffolk breed compared to the Charolaise breed $(P<0.05)$. The concentration of NEU in the blood of the Lithuanian Blackheaded breed was by $35.84 \%$ lower compared to the Merino breed $(P<0.05)$. The RBC of the Suffolk breed was by $12.09 \%$ higher compared to the Charolaise breed, by $15.37 \%$ higher compared to the Merino breed, and by $20.34 \%$ higher compared to the Lithuanian Blackheaded breed $(P<0.05)$.

The highest concentration of HGB was determined in the Suffolk breed and the lowest (by $15.66 \%$ lower $)$ in the Merino breed $(P<0.05)$. The highest HCT level was found in the Suffolk breed and the lowest (by 17.68\% lower) in the Lithuanian Blackheaded breed $(P<0.05)$. 
Table 1. The effect of the temperature-humidity index and breed on morphological blood indices.

\begin{tabular}{|c|c|c|c|c|c|c|c|}
\hline \multicolumn{4}{|c|}{ Morphological blood indices by THI class } & \multicolumn{4}{|c|}{ Morphological blood indices by breed } \\
\hline Blood indices & THI class & S M & SE & Blood indices & Breed & M & SE \\
\hline \multirow[t]{4}{*}{$\mathrm{WBC} \times 10^{9} / 1$} & 1 & $54.61^{\mathrm{a}}$ & 0.321 & \multirow[t]{4}{*}{$\mathrm{WBC} \times 10^{9} / 1$} & Lithuanian Blackheaded & $5.77^{\mathrm{a}}$ & 0.528 \\
\hline & 2 & $62.42^{\mathrm{b}}$ & 0.188 & & Merino & $6.42^{\mathrm{a}}$ & 0.491 \\
\hline & & & & & Charolaise & $5.39^{\mathrm{a}}$ & 0.615 \\
\hline & & & & & Suffolk & $6.40^{\mathrm{a}}$ & 0.435 \\
\hline \multirow[t]{4}{*}{$\mathrm{LYM} \times 10^{9} / 1$} & 1 & $35.30^{\mathrm{a}}$ & 0.185 & \multirow[t]{4}{*}{$\mathrm{LYM} \times 10^{9} / 1$} & Lithuanian Blackheaded & $3.88^{\mathrm{ab}}$ & 0.296 \\
\hline & & & & & Merino & $3.52^{\mathrm{ab}}$ & 0.275 \\
\hline & 2 & $36.56^{\mathrm{a}}$ & 0.147 & & Charolaise & $3.05^{\mathrm{b}}$ & 0.345 \\
\hline & & & & & Suffolk & $3.97^{\mathrm{a}}$ & 0.244 \\
\hline \multirow[t]{4}{*}{$\mathrm{MON} \times 10^{9} / 1$} & 1 & $0.28^{\mathrm{a}}$ & 0.015 & \multirow[t]{4}{*}{$\mathrm{MON} \times 10^{9} / 1$} & Lithuanian Blackheaded & $0.30^{\mathrm{a}}$ & 0.027 \\
\hline & & & & & Merino & $0.32^{\mathrm{a}}$ & 0.025 \\
\hline & 2 & $0.31^{\mathrm{a}}$ & 0.010 & & Charolaise & $0.26^{\mathrm{a}}$ & 0.031 \\
\hline & & & & & Suffolk & $0.32^{\mathrm{a}}$ & 0.022 \\
\hline \multirow[t]{4}{*}{$\mathrm{NEU} \times 10^{9} / 1$} & 1 & $19.28^{\mathrm{a}}$ & 0.190 & \multirow[t]{4}{*}{$\mathrm{NEU} \times 10^{9} / 1$} & Lithuanian Blackheaded & 1.88 & 0.319 \\
\hline & & & & & Merino & $2.93^{\mathrm{b}}$ & 0.296 \\
\hline & 2 & $27.07^{b}$ & 0.111 & & Charolaise & $2.3^{\mathrm{ab}}$ & 0.372 \\
\hline & & & & & Suffolk & $2.4^{\mathrm{ab}}$ & 0.263 \\
\hline \multirow[t]{4}{*}{$\mathrm{RBC} \times 10^{12} / 1$} & 1 & $108.12^{\mathrm{a}}$ & 0.264 & \multirow[t]{4}{*}{$\mathrm{RBC} \times 10^{12} / 1$} & Lithuanian Blackheaded & $9.95^{\mathrm{a}}$ & 0.477 \\
\hline & & & & & Merino & $10.57^{\mathrm{a}}$ & 0.443 \\
\hline & 2 & $115.97^{b}$ & 0.143 & & Charolaise & $10.98^{\mathrm{a}}$ & 0.556 \\
\hline & & & & & Suffolk & $12.49^{b}$ & 0.393 \\
\hline \multirow[t]{4}{*}{ HGB g/l } & 1 & $128.49^{a}$ & 2.833 & \multirow[t]{4}{*}{ HGB $g / 1$} & Lithuanian Blackheaded & $122.79^{a}$ & 4.745 \\
\hline & & & & & Merino & $117.77^{\mathrm{a}}$ & 4.409 \\
\hline & 2 & $130.54^{\mathrm{a}}$ & 1.562 & & Charolaise & $139.64^{b}$ & 5.527 \\
\hline & & & & & Suffolk & $141.93^{b}$ & 3.908 \\
\hline \multirow[t]{4}{*}{ НCТ \% } & 1 & $333.58^{\mathrm{a}}$ & 0.747 & \multirow[t]{4}{*}{ НCТ \% } & Lithuanian Blackheaded & $30.92^{\mathrm{a}}$ & 1.244 \\
\hline & & & & & Merino & $31.888^{b}$ & 1.156 \\
\hline & 2 & $339.84^{\mathrm{a}}$ & 0.386 & & Charolaise & $34.70^{c}$ & 1.449 \\
\hline & & & & & Suffolk & $37.56^{\mathrm{c}}$ & 1.024 \\
\hline \multirow[t]{4}{*}{ MCV fl } & 1 & $31.00^{\mathrm{a}}$ & 0.403 & \multirow[t]{4}{*}{ MCV fl } & Lithuanian Blackheaded & $31.00^{\mathrm{ab}}$ & 0.543 \\
\hline & & & & & Merino & $30.68^{\mathrm{ab}}$ & 0.504 \\
\hline & 2 & $29.48^{b}$ & 0.190 & & Charolaise & $31.50^{\mathrm{b}}$ & 0.632 \\
\hline & & & & & Suffolk & $29.71^{\mathrm{a}}$ & 0.447 \\
\hline \multirow[t]{4}{*}{$\mathrm{MCH}$ pg } & 1 & $11.98^{\mathrm{a}}$ & 0.172 & \multirow[t]{4}{*}{$\mathrm{MCH}$ pg } & Lithuanian Blackheaded & $12.38^{\mathrm{ab}}$ & 0.292 \\
\hline & & & & & Merino & $11.22^{\mathrm{b}}$ & 0.271 \\
\hline & 2 & $11.30^{\mathrm{b}}$ & 0.096 & & Charolaise & $12.94^{\mathrm{a}}$ & 0.34 \\
\hline & & & & & Suffolk & $11.26^{\mathrm{bc}}$ & 0.24 \\
\hline \multirow[t]{4}{*}{$\mathrm{MCHC}$ g/l } & 1 & $386.27^{\mathrm{a}}$ & 5.479 & \multirow[t]{4}{*}{ MCHC g/1 } & Lithuanian Blackheaded & $399.53^{\mathrm{a}}$ & 9.740 \\
\hline & & & & & Merino & $368.27^{b}$ & 9.051 \\
\hline & 2 & $384.26^{\mathrm{a}}$ & 2.888 & & Charolaise & $409.50^{c}$ & 11.347 \\
\hline & & & & & Suffolk & $376.86^{\mathrm{ab}}$ & 8.023 \\
\hline $\mathrm{PLT} \times 10^{9} / 1$ & 1 & $180.2^{\mathrm{a}}$ & 16.816 & $\mathrm{PLT} \times 10^{9} / 1$ & Lithuanian Blackheaded & 187.2 & 51.444 \\
\hline & & & & & Merino & 215.18 & 47.808 \\
\hline & 2 & $288.19^{b}$ & 16.103 & & Charolaise & 201.14 & 59.931 \\
\hline & & & & & Suffolk & 228.71 & 42.377 \\
\hline
\end{tabular}

a,b,c Values between groups with different superscripts differ significantly at $P<0.05$

RBC - erythrocytes; HGB - haemoglobin; HCT - haematocrit; MCV - mean corpuscular volume; MCH - mean corpuscular haemoglobin; MCHC - mean corpuscular haemoglobin concentration; WBC - leukocytes; NEU neutrophils; LYM - lymphocytes; MON - monocytes; PLT - platelet count; THI 1 - temperature-humidity index class $1(20>$ THI $>10)$; THI 2 - temperature-humidity index class 2 (THI $\geq 20) ; \mathrm{M}$ - mean; SE - standard error 
The MCV of the Charolaise breed was by $6.02 \%$ higher compared to that in the Suffolk breed $(P<0.05)$. The highest concentration of $\mathrm{MCH}$ was estimated in the Charolaise breed and the lowest (by $13.29 \%$ lower) in the Merino breed $(P<0.05)$.

The highest mean MCHC value was found in the Charolaise breed and the lowest (by $10.07 \%)$ in the Merino breed $(P<0.05)$. No significant differences in the mean PLT between breeds were identified.

Multivariate test showed a significant effect of the THI on NEU $(P<0.05)$, a significant effect of the breed on NEU $(P<0.05)$, RBC $(P<0.05)$, HGB $(P<0.05)$ and MCHC $(P<0.05)$. A significant effect of the interaction between the breed and the THI class was estimated in relation to $\mathrm{NEU}(P<0.05)$ and $\mathrm{MCH}(P<0.05)$.

The effect of THI on BHB in diferent sheep breeds

The concentration of BHB in group THI 2 was by $12.9 \%$ higher $(P<0.05)$ compared to group THI 1. The results of the breed analysis showed the lowest BHB concentration in the Charolaise breed and the highest (by 63.64\% higher) in the Merino breed $(P<0.05$, Fig. 1). A significant effect of the breed $(P<0.05)$ and the THI class $(P<0.05)$ on the BHB was determined, whereas the effect of breed interaction with the THI was found to be non-significant.

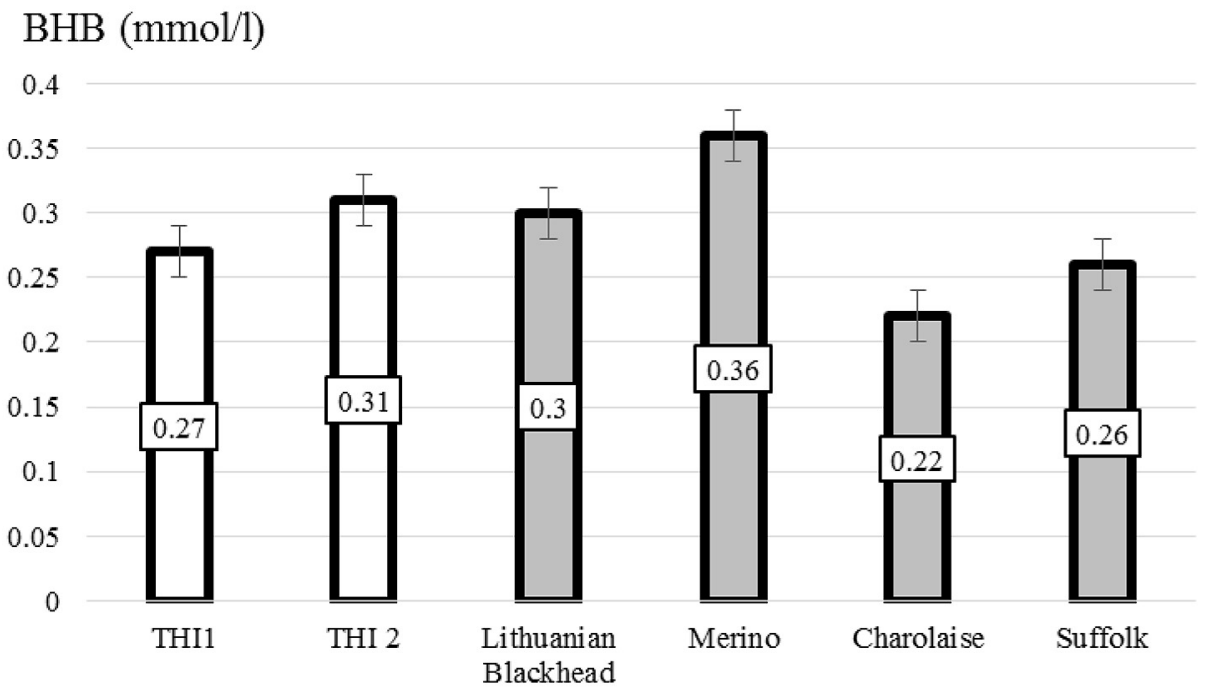

Fig. 1. $\beta$-hydroxybutyrate by temperature-humidity index class and breed

THI 1 - temperature-humidity index class $1(20>$ THI $>10)$; THI 2 - temperature-humidity index class 2 (THI $\geq 20$ ); BHB - $\beta$-hydroxybutyrate

The effect of the THI on the correlation coeficient between BHB and blood morfological indicators

The BHB levels in both THI classes were positively corelated with WBC, LYM and MON and negatively corelated with RBC $(P<0.05)$, HGB $(P<0.05)$, and HCT (Plate I, Fig. 2). 


\section{Discussion}

The aim of the study was to determine the effect of temperature and humidity on blood morphological indices and BHB and the difference in blood morphology between four different sheep breeds.

Evaluation of haematological indices can be an important tool of checking on animal welfare, since blood is an important response indicator to climatic changes (Okourwa 2015). Ribeiro et al. (2018) noted that thermal conditions, especially those associated with seasonal periodicity, may directly affect the changes in blood indices. Significant differences between the WBC, NEU, RBC, MCV, MCH, and PLT values between the THI groups were determined. The THI could be used as an indicator of climatic conditions (Gaughan et al. 2011). It was found that in group THI 1, the mean values of MCHC $(5.68 \%, P<0.05), \mathrm{MCH}(0.52 \%)$, and $\mathrm{HCT}(4.90 \%, P<0.05)$ were higher compared to group THI 2. The average values of other blood morphological indicators were higher in group THI 2 compared to group THI 1. In addition, the decrease in $\mathrm{MCH}, \mathrm{MCHC}$ and HCT levels in group THI 2 could be due to an increased attack of free radicals on the erythrocyte membrane which is rich in lipid content, and ultimate lysis of RBC or inadequate nutrient availability for haemoglobin synthesis as the animal decreased voluntary intake under thermal stress (Bezerra et al. 2008; Al-Eissa et al. 2012). The decrease in HCT might be due to the haemodilution effect where more water is transported into the circulatory system for evaporative cooling (El-Nouty et al. 1990). However, the results of several experiments showed higher PCV levels at higher ambient temperatures and humidity (McManus et al. 2011). Higher PCV could be an adaptive mechanism to provide water necessary for the evaporative cooling process (Al-Haidary 2004). When higher ambient temperature and humidity causes direct reduction in $\mathrm{HGB}$ or s simultaneous decrease of HCT, a decrease in $\mathrm{MCH}$ and MCHC may be observed (Habibu et al. 2017). Despite a few exceptions, the decrease in $\mathrm{MCH}$ and $\mathrm{MCHC}$ is the most common finding in livestock during thermal stress (Banerjee et al. 2014).

Significant differences that were found for WBC, NEU, RBC, MCV, and PLT were inversely proportional to the increasing temperature and humidity, findings that were similar to those by other researchers (Pereira et al. 2008). High THI values affect both erythrocyte and leukocyte counts (Banerjee et al. 2014; Habibu et al. 2017b). Most studies in livestock reported an increase in the total leukocyte count primarily due to an increase in neutrophil and monocyte counts, with a few others reporting an increase in the majority of leukocyte components during higher temperature and humidity exposure (Whitehead and Keller 2003). Leukocytosis has been associated with thermal stress in sheep, which difference may be attributed to the age of the animals used in the studies (McManus et al. 2011). Several factors such as sheep breed and seasonal variations can affect the pattern of haematological values (Bezerra et al. 2008; Al-Eissa et al. 2012). In the present research, significant differences weer found for LYM, RBC, HGB, HCT, $\mathrm{MCV}, \mathrm{MCH}, \mathrm{MCHC}$ between the sheep breeds. The blood results obtained in the study are in accordance with the analysis carried out by Winnicka (2008). Multivariate test showed a significant effect of breed on NEU $(P<0.05)$, RBC $(P<0.05)$, HGB $(P<$ $0.05)$, and $\mathrm{MCHC}(P<0.05)$. No significant differences in the mean PLT between the breeds were found in the present study. A significant increase $(P<0.05)$ in RBC, HGB, HCT was determined in the Suffolk sheep breed. Therefore, significant differences in $\mathrm{RBC}, \mathrm{HGB}, \mathrm{HCT}$ were related to the sheep breed. As the animals were able to dissipate efficiently the excess temperature and humidity, the effects of thermal challenge may have been mitigated by these blood indices (Correa et al. 2012). Any changes in the $\mathrm{HGB}, \mathrm{PCV}$, and $\mathrm{RBC}$ are directly reflected in the $\mathrm{MCH}$ and $\mathrm{MCHC}$. When there is a simultaneous increase in the $\mathrm{HGB}, \mathrm{PCV}$ and $\mathrm{RBC}$ during a change in thermal conditions, 
the MCH and MCHC increase (Hashem 2014). Lower values of NEU and WBC $(P<0.05)$ were determined in the Lithuanian Blackheaded and Charolaise breeds. It may be indicative of a higher THI tolerance and adaptation to enviromental conditions (Correa et al. 2012). Some sheep breeds presented coat characteristics that facilitate convective and evaporative thermolysis on the skin surface. This may have contributed to greater resistance to higher ambient temperature and humidity (Titto et al. 2016).

The BHB concentration in group THI 2 was by $12.9 \%$ higher $(P<0.05)$ compared to group THI 1. An excessive concentration of serum BHB cannot be utilized by extrahepatic tissue, and therefore the serum BHB level remains high (Aleena et al. 2016). In this way, the THI also affect BHB concentration in the blood. According to the results of the breed analysis, the lowest BHB concentration was estimated in the Charolaise breed and the highest (by $63.64 \%$ higher) was found in the Merino breed $(P<0.05)$. These findings may be considered as metabolic adaptive responses (Al-Dawood 2017). In the present study, a significant effect of the breed $(P<0.05)$ and the THI class $(P<0.05)$ on the BHB was determined, whereas the effect of the breed interaction with the THI was found to be nonsignificant.

Based on the study results, it can be concluded that the response to temperature and humidity is dependent on the animal breed. It was found that both morphological blood indices and $\beta$-hydroxybutyrate play an important role in terms of the effects of the THI. It would be useful to undertake further studies to examine other effects of temperature and humidity.

\section{References}

Al-Dawood A 2017: Effect of heat stress on adipokines and some blood metabolites in goats from Jordan. Anim Sci J 88: 356-363

Aleena J, Pragna P, Archana PR, Sejian V, Bagath M, Krishnan G, Manimaran A, Beena V, Kurien EK, Varma G, Bhatta R 2016: Significance of metabolic response in livestock for adapting to heat stress challenges. Asian J Anim Sci 10: 224-234

Al-Eissa MS, Alkahtani S, Al-Farraj SA, Alarifi SA, Al-Dahmash B, Al-Yahya H 2012: Seasonal variation effects on the composition of blood in Nubian ibex (Capra nubiana) in Saudi Arabia. Afr J Biotechnol 11: 1283-1286

Al-Haidary AA 2004: Physiological responses of Naimey sheep to heat stress challenge under semi-arid environments. Int J Agric Biolog 2: 307-309

Banerjee D, Upadhyay RC, Chaudhary UB, Kumar R, Singh S, Ashutosh Das TK 2014: Seasonal variations in physio-biochemical profiles of Indian goats in the paradigm of hot and cold climate. Biol Rhythm Res 46: 221-236

Beatty DT, Barnes A, Fleming PA, Taylor E, Malo-ney SK 2008: The effect of fleece on core and rumen temperature in sheep. J Therm Biol 33: 437-443

Bezerra LR, Ferreira AF, Camboim EKA, Justiniano SV, Machado PCR, Gomes BB 2008: Perfil hematológico de cabras clinicamente sadias criadas no Cariri paraibano. Ciência e Agrotecnologia 32: 955-960

Caroprese M 2008: Sheep housing and welfare. Small Rumin Res 76: 21-25

Correa MPC, Cardoso MT, Castanheira M 2012: Heat tolerance in three genetic groups of lambs in central Brazil. Small Rumin Res 104: 70-77

El-Nouty FD, Al-Haidary AA, Salah MS 1990: Seasonal variations in hematological values of high-and averageyielding Holstein cattle in semi-arid environment. J King Saudi Univ Agric Sci 2: 173-182

Gaughan J, Mader T, Gebremedhin K 2011: Rethinking heat index tools for livestock. In: Collier RJ, Collier JL. Environmental physiology of livestock. West Sussex, UK, Wiley-Blackwell, pp. 243-265

Habibu B, Makun HJ, Yaqub LS, Buhari HU, Aluwong T, Kawu MU 2017: Comparative evaluation of haematological parameters and erythrocyte membrane stability in pregnant and lactating goats in different seasons of tropical Savannah. Theriogenology 99: 30-35

Hashem ALS 2014: Effect of summer shearing on thermoregulatory, hematological and cortisol responses in Balady and Damascus goats in desert of Sinai, Egypt. World Appl Sci J 30: 521-533

Marai IFM, Haeeb AAM 2010: Buffalo's biological functions as affected by heat stress - a review. Livest Sci 127: 89-109

Marai IFM, El-Darawany AA, Fadiel A, Abdel-Hafez MAM 2007: Physiological traits as affected by heat stress in sheep. Small Rum Res 71: 1-12

McManus C, Louvandini H, Paim T 2011: The challenge of sheep farming in the tropics: Aspects related to heat tolerance. Braz J Anim Sci 40: 107-120 
McManus C, Paludo G, Louvandini H 2009: Heat tolerance in Brazilian sheep: Physiological and blood parameters. Trop Anim Health Prod 41: 95-101

Okourwa MI 2015: Effect of coat characteristics on physiological traits and heat tolerance of West African dwarf sheep in Southern Nigeria. Open J Anim Sci 5: 351-357

Pereira AMF, Baccari FJR, Titto EAL, Almeida JAA 2008: Effect of thermal stress on physiological parameters, feed intake and plasma thyroid hormones concentration in Alentejana, Mertolenga, Frisian and Limousine cattle breeds. Int J Biometeorol 52: 199-208

Ribeiro NL, Costa RG, Pimenta Filho EC, Ribeiro MN, Bozzi R 2018: Effects of the dry and the rainy season on endocrine and physiologic profiles of goats in the Brazilian semi-arid region. Ital J Anim Sci 17: 454-461

Salama AAK, Caja G, Hamzaoui S, Badaoui B, Castro-Costa A, Façanha DAE, Guilhermino MM, Bozzi R 2014: Different levels of response to heat stress in dairy goats. Small Rumin Res 121: 73-79

Srikandakumar A, Johnson EH, Mahgoub 2003: Effect of heat stress on respiratory rate, rectal temperature and blood chemistry in Omani and Australian Merino sheep. Small Rumin Res 49: 193-198

Titto CG, Verissimo CJ, Pereira AMF, Geraldo AM, Katiki LM, Titto EAL 2016: Thermoregulatory response in hair sheep and shorn wool sheep. Small Rumin. Res 144: 341-345

Whitehead CC, Keller T 2003: An update on ascorbic acid in poultry. Worlds Poult Sci J 59: 161-184

Winnicka A 2008: Reference Values of Basic Laboratory Tests in Veterinary Medicine. Fourth edn (in Polish). SGGW Press, Warsaw, Poland 
Plate I

Autukaite J. et al.: The impact ... pp. 247-254

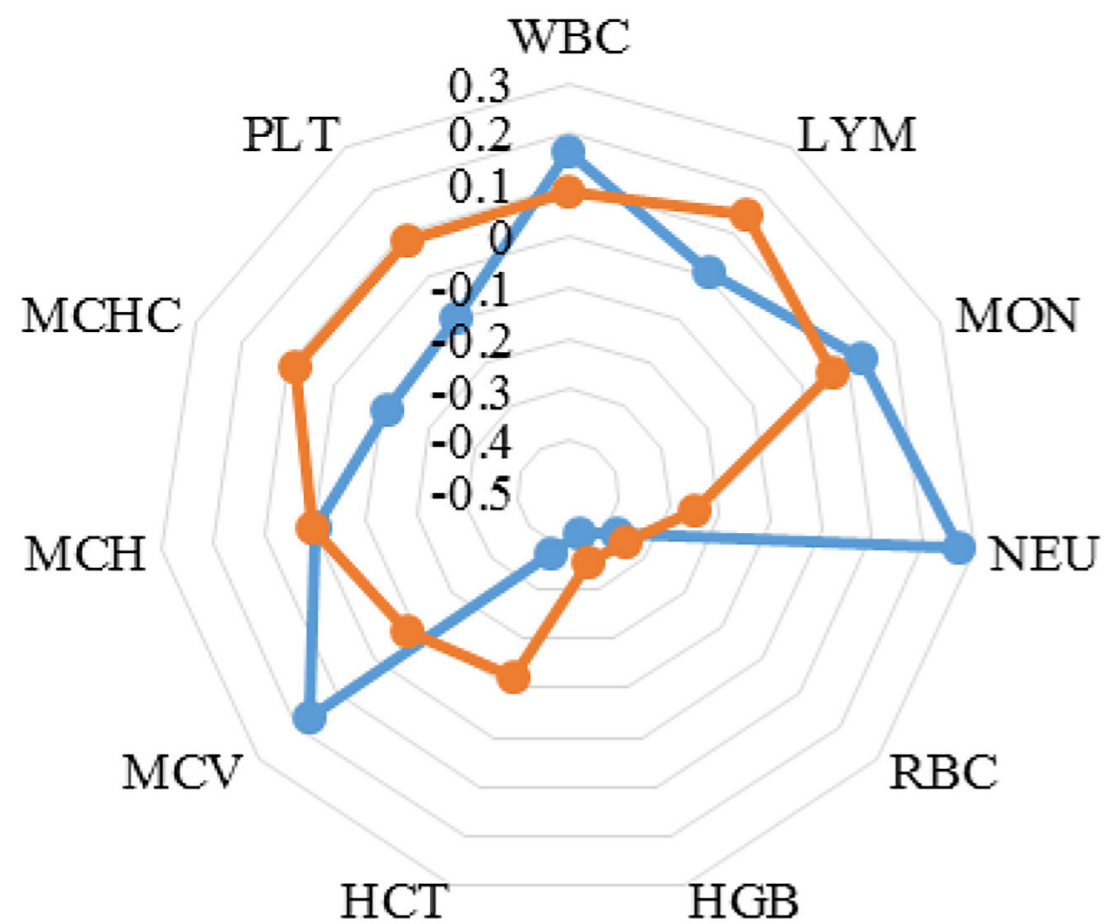

Fig. 2. $\beta$-hydroxybutyrate correlation with blood indices by the temperature-humidity index class

RBC - erythrocytes; HGB - haemoglobin; HCT - haematocrit; MCV - mean corpuscular volume; $\mathrm{MCH}$ - mean corpuscular haemoglobin; MCHC - mean corpuscular haemoglobin concentration; WBC - leukocytes; NEU neutrophils; LYM - lymphocytes; MON - monocytes; PLT - platelet count; THI 1 - temperature-humidity index class $1(20>$ THI $>10)$; THI 2 - temperature-humidity index class $2(\mathrm{THI} \geq 20)$; 